\title{
An Antimicrobial Peptide-Loaded Chitosan/Polyethylene Oxide Nanofibrous Membrane Fabricated by Electrospinning Technology
}

\author{
Ling $Y u^{1}$, Shubin Dou ${ }^{2}$, Jinghan $\mathrm{Ma}^{1}$, Qiang Gong ${ }^{1}$, Mogen Zhang ${ }^{1}$, Xiquan Zhang ${ }^{2 *}$, \\ Min $\mathrm{Li}^{3 *}$ and Weifen Zhang ${ }^{1,4,5 *}$ \\ ${ }^{1}$ College of Weifang Medical University, Weifang, China, ${ }^{2}$ All Military Interventional Diagnosis and Treatment Center, 960th \\ Hospital of Chinese People's Liberation Army, Zibo, China, ${ }^{3}$ All Military Interventional Diagnosis and Treatment Center, 960th \\ Hospital of Chinese People's Liberation Army, Jinan, China, ${ }^{4}$ Institute for Smart Materials and Regenerative Medicine, School \\ of Pharmacy, Weifang Medical College, Weifang, China, ${ }^{5}$ Shandong Engineering Research Center for Smart Materials and \\ Regenerative Medicine, Weifang, China
}

OPEN ACCESS

Edited by:

Magdalena M. Stevanović, Institute of Technical Sciences

(SASA), Serbia

Reviewed by:

Hualin Wang,

Hefei University of Technology, China

Junchao Wei,

Nanchang University, China

${ }^{*}$ Correspondence:

Xiquan Zhang

zyfbb19901024@sina.com

$\mathrm{Min} \mathrm{Li}$

liminyingxiang@163.com

Weifen Zhang

zhangwf@wfmc.edu.cn

Specialty section:

This article was submitted to Biomaterials,

a section of the journal

Frontiers in Materials

Received: 07 January 2021 Accepted: 23 February 2021 Published: 19 March 2021

Citation:

Yu L, Dou S, Ma J, Gong Q, Zhang M, Zhang X, Li M and Zhang W (2021) An Antimicrobial Peptide-Loaded Chitosan/Polyethylene Oxide Nanofibrous Membrane Fabricated by Electrospinning Technology. Front. Mater. 8:650223.

doi: 10.3389/fmats.2021.650223
Antimicrobial peptides (AMPs) are a new class of promising antibacterial agents. We prepared electrospinning chitosan (CS)-polyethylene oxide (PEO) nanofiber membranes containing different concentrations of an antibacterial peptide NP10. The average diameter of nanofibers increased with the total concentration of NP10. The FTIR shows that all the peaks of CS-PEO nanofiber membranes with different concentrations of NP10 were almost the same as those of pure CS-PEO nanofiber membranes, and only the peak intensity changes. Adding NP10 can improve the thermal stability of CS-PEO nanofiber membranes. In the in vitro release experiment, NP10 was released from the CS-PEO-0.5\%NP10 nanofiber membrane in a burst first and then slowly and continuously. Simultaneously, the CS-PEO-NP10 nanofiber membrane had good antibacterial activity against Escherichia coli and Staphylococcus aureus and good biocompatibility. In animal wound healing experiments, CS-PEO-0.5\%NP10 nanofiber membrane had advantages over gauze and CS-PEO nanofiber membrane in wound healing. These properties may provide a choice for the clinical application of AMPs and treatment of wound infections.

Keywords: chitosan, antibacterial peptide, electrostatic spinning, antibacterial agent, wound infection

\section{INTRODUCTION}

Worldwide, armed conflict is a significant contributor to the global burden of disease (Murray et al., 2002). Conflict-related injuries often result in contaminated soft tissue and bone, leading to severe infection and death (Fares et al., 2013; Blyth et al., 2015). The cornerstones of war wound management are surgical intervention and antibiotic therapy. Surgical interventions, mainly debridement of devitalized or infected tissue, are performed according to treatment principles for traumatic wounds (Giannou and Baldan, 2010). In war environments, wound care may not only be delayed but may also need to be self-administered or facilitated by untrained personnel (Champion et al., 2003). In this case, antibiotic therapy is critical. Antibiotic treatment is utilized both as perioperative prophylaxis and as part of the treatment of wound infections (Giannou and Baldan, 2010; Sahli et al., 2016). However, the over and misuse of antibiotics increase the rate of antibiotic resistance globally (World Health Organization, 2014; Sahli et al., 2016), threatening the effectiveness of available antibiotics. With the rise in antibiotic-resistant 
superbugs such as methicillin-resistant Staphylococcus aureus $(M R S A)$, the infections caused by drug-resistant pathogens prolong the treatment duration and increase the nursing costs (Rice, 2008; Infectious Diseases Society of America (IDSA) et al., 2011). Therefore, there is an imperious need for new alternative antibacterial materials and approaches to treat and prevent multidrug-resistant infections.

Several new antibacterial methods have merged in recent years, including metal ions/oxides, quaternary ammonium compounds, and antimicrobial peptides (AMPs) (Martí et al., 2018). AMPs are a new and promising class of antimicrobial agents with a low tendency to induce resistance in vitro (Hancock, 1997; Zasloff, 2002; Gordon et al., 2005). AMPs exhibit little drug resistance and other significant advantages, involving high efficiency, rapid sterilization, small molecular weight, appropriate thermal stability, no immunogenicity, and low sensitivity to enzymatic hydrolysis (Dewangan et al., 2018; Zhao et al., 2018). To date, hundreds of AMPs have been discovered, which generally cationic peptides with $10-50$ amino acids in length. However, AMPs need to overcome several vital problems before clinical application. These AMPs are cationic and amphiphilic. It can also bind host components, such as extracellular proteins, lipoproteins, etc. This characteristic leads to a decrease in the bioavailability of AMPs. Some of these peptides have shown harmful side effects at active antimicrobial concentrations, such as lysis of red blood cells (Johansson et al., 1998; Pacor et al., 2002). When the chemotactic activities of cathelicidin, defensin, and chemokine overlap, the innate immunity will be affected. And its wound-healing ability may be impaired (Andersson et al., 2016). Besides, there are reports in the literature that AMPs have nephrotoxicity and neurotoxicity when administered intravenously. Thus, local delivery of drugs or AMPs in a spaced and sustainable way has a significant advantage over a systemic administration. It improves the effectiveness of antimicrobial treatment and selective targeting and reduces side effects on tissues.

An optimal dressing for local delivery is defined as maintaining high humidity at the wounded site while removing excess exudate. Simultaneously, it is non-toxic or non-allergenic, prevents microbial invasion, allows oxygen exchange, comfort, and low cost (Jones et al., 2006; Abrigo et al., 2014). Electrospinning is a mature technology that can stably produce fibers in the sub-micron range. It also has a too high surfaceto-volume ratio, adjustable porosity, and ductility to adapt to various sizes and shapes. The ability to control the fiber's composition to achieve desired properties and functionality could contribute significantly to our work (Huang and Chang, 2003; Lannutti et al., 2007; Liang et al., 2007; Hunley and Long, 2008; Abrigo et al., 2014). It also avoids wound healing interference, reducing bacterias resistance and the frequency of dressing changes (Jannesari et al., 2011). Electrospinning has recently been recognized as the latest method that can be effectively combined with AMPs (Mangoni et al., 2016; Felgueiras and Amorim, 2017). At present, there are few reports of combining antimicrobial peptides with electrospinning (Dart et al., 2019). In the process of electrospinning, the choice of carrier polymer is also crucial. The wrong choice may result in low burst release or no release at all, and AMP inactivation reduces drug absorption. For example, polycaprolactone nanofiber membrane loaded with AMP loses antibacterial properties (Dart et al., 2019). Chitosan (CS) and polyethylene oxide (PEO) have excellent properties, such as non-toxic, biodegradable, and biocompatible. Besides, CS has hemostatic activity and anti-infective ability (Jin et al., 2002; Fan et al., 2016; Guan et al., 2016; Li et al., 2016). So far, there have been many reports on the successful preparation of CS-PEO nanofiber membranes, such as the addition of lauric arginate (Deng et al., 2018) and ZIF-8 nanoparticles (Kohsari et al., 2016a) for antibacterial and food safety CS-PEO nanofiber membranes. However, there is no report on AMPs and CS/PEO's effective combination to prepare nanofiber membranes (Dart et al., 2019). In this study, CS and PEO were selected as the materials for preparing wound dressings loaded with AMP NP10.

According to statistics by Dar et al., among the 18 studies that have been reported to combine AMPs with electrospinning technology effectively, only nine have conducted in vitro biocompatibility experiments. And there are fewer in vivo experiments, with only three studies. In our research, we prepared electrospun CS-PEO nanofiber membranes containing different concentrations of antimicrobial peptide NP10. We will systematically study its characterization, in vitro biocompatibility, antibacterial ability, and wound healing ability in animals. It can provide a new possibility of an effective combination with CS-PEO nanofiber membrane for the clinical application of AMPs. And add evidence for the nanofiber membrane loaded with AMPs to treat wound infections and promote wound healing.

\section{MATERIALS AND METHODS}

\section{Materials}

Antibacterial peptides NP10 synthesized by the NANOPEPTIDE Bio-Technology Co., Ltd. (Qingdao, China). Chitosan ( $\mathrm{Mw}=$ $1.2 \times 10^{5} \sim 1.5 \times 10^{5}$ ) was purchased from the Haili Biological Products Co., Ltd. (Laizhou, China). Polyethylene oxide ( $\mathrm{Mw}=$ $4 \times 10^{6}$ ) was purchased from the West Asia Chemical Co., Ltd. (Jinan, China). Acetic acid was purchased from the Far East Fine Chemical Co., Ltd. 3-(4,5-dimethyl-thiazol-2-yl)-2,5-diphenyltetrazolium bromide (MTT) were from Aladdin Industrial Co., Ltd. (China). Hacat cells were purchased from the Procell Life Science\&Technology Co., Ltd. (Wuhan, China) and cultured in RPMI 1640 medium (Solarbio, China) supplemented with 10\% fetal bovine serum (Hyclone, USA), $100 \mathrm{U} / \mathrm{mL}$ penicillin and 100 $\mathrm{mg} / \mathrm{mL}$ streptomycin. Cells were maintained at $37^{\circ} \mathrm{C}$ with $5 \%$ $\mathrm{CO}_{2}$ in a humidified incubator. Staphylococcus aureus (S. aureus) and Escherichia coli (E. coli) were obtained from Weifang Medical University. All other chemicals used were of analytical grade and were obtained from Chemical Reagent Co., Ltd. (Beijing, China).

\section{Fabrication of the Nanofiber Membranes}

Chitosan and polyethylene oxide were mixed and dissolved in a $1 \%$ acetic acid solution at a ratio of $50: 50$ to prepare a 30 $\mathrm{mg} / \mathrm{mL}$ solution. Then put it on a magnetic stirrer overnight to form a homogeneous solution. In the same way, we added 
1,3 , and $5 \mathrm{mg} / \mathrm{mL}$ antibacterial peptides NP10 on this basis so that they form a uniform solution under magnetic stirring. The electrostatic spinning machine (Ucalery) was purchased from Beijing Yongkang Leye Technology Development Co., Ltd. A constant electric field of $10 \mathrm{kV}$ was applied to the polymer solution. The collector was placed $18 \mathrm{~cm}$ from the polymer solution. We used a $10 \mathrm{~mL}$ syringe to load the polymer solution and prepared the nanofiber membrane at a speed of $0.04 \mathrm{~mm} / \mathrm{min}$. The relative humidity was kept constant, $25 \pm$ $5 \%$, and the temperature was $25 \pm 5^{\circ} \mathrm{C}$. We prepared four groups of CS-PEO, CS-PEO-0.1\% NP10, CS-PEO-0.3\% NP10, and CS-PEO-0.5\% NP10 nanofiber membranes.

\section{Scanning Electron Microscopy of Electrospun Fibers}

Images of the nanofibers were recorded with a JEOL JSM 3600 (UK) scanning electron microscope (SEM). Samples were coated with a thin layer of gold to increase conductivity. Fiber diameters were determined using the Image J software, with a minimum of 50 measurements per sample from samples electrospun.

\section{Fourier Transform Infrared (FT-IR) Spectroscopy Analysis}

The prepared nanofiber membrane's chemical structure was characterized using Fourier transform infrared spectrometer (FT-IR, VERTEX70, Bruker AXS, Germany). The spectra were obtained in the range of $500-4,000 \mathrm{~cm}^{-1}$. The products of the nanofiber membrane were stored at an ambient temperature of $25^{\circ} \mathrm{C}$.

\section{Thermogravimetric Analysis (TGA)}

Thermogravimetric analysis (TA-60WS, TA, USA) was used to determine the thermogravimetric analysis of pure materials and nanofiber membranes. In a dry nitrogen atmosphere, the sample was scanned in the temperature range of $40-600^{\circ} \mathrm{C}$ at a heating rate of $10^{\circ} \mathrm{C} / \mathrm{min}$.

\section{In vitro NP10 Release Experiments}

The CS-PEO nanofiber membrane containing $0.5 \%$ NP10 was used to study the release property. The amounts of drug released from the nanofiber membrane were determined by UVvisible spectrophotometer at wavelength $220 \mathrm{~nm}$. Each specimen $(30 \mathrm{mg})$ was immersed in $8 \mathrm{~mL}$ phosphate buffer saline (PBS, $0.01 \mathrm{M}, \mathrm{pH}=7.2-7.4$ ) and was then shaken in an incubator for 15 days at $37^{\circ} \mathrm{C}$. To evaluate drug molecules' accumulative release, the solution $(1 \mathrm{~mL})$ was extracted at different time intervals, and fresh PBS $(1 \mathrm{~mL})$ was instead added into the release solution for continuing incubation. All the experiments were performed in triplicate.

\section{Hemolysis Assay of Nanofiber Membrane}

We perform the hemolysis assay using fresh, healthy human blood, and the blood sample is from the PLA 960th Hospital. We collect the erythrocytes via centrifugation at 1,500 rpm for $10 \mathrm{~min}$ and wash three times with saline. We prepare the stock dispersion by mixing $3 \mathrm{~mL}$ of centrifuged erythrocytes into $11 \mathrm{~mL}$ of saline. We put a $6 \mathrm{mg}$ nanofiber membrane into $1 \mathrm{~mL}$ physiological saline to obtain the extract. We add $100 \mu \mathrm{L}$ of a section to $1 \mathrm{~mL}$ of stock dispersion, then we mix the solutions and incubate them for $3 \mathrm{~h}$ at $37^{\circ} \mathrm{C}$. Further, we measure the percentage of hemolysis by UV-vis analysis of the supernatant at $540 \mathrm{~nm}$ absorbance after centrifugation at $12,00 \mathrm{rpm}$ for $15 \mathrm{~min}$. Saline is the negative control, and pure water $(18.2 \mathrm{M} \Omega \bullet \mathrm{cm})$ is a positive control. We calculate the percentage of hemolysis with the following formula:

$$
\text { hemolysis }(\%)=\frac{\mathrm{AS}-\mathrm{AN}}{\mathrm{AP}-\mathrm{AN}} \times 100 \%
$$

where AS is the absorbance resulting from the addition of nanofiber membrane extract to the erythrocyte suspension, AN is the absorbance following the addition of saline as a negative control, and AP is the absorbance following the addition of pure water as a positive control.

\section{MTT Assay}

To investigate the potential cytotoxicity of the nanofiber membrane, the cell viability was analyzed by using the Hacat cell lines in an MTT assay. Hacat cells were seeded into 96well plates at a concentration of $1 \times 10^{4}$ cells/well. Cells were incubated at $37^{\circ} \mathrm{C}$ and $5 \% \mathrm{CO}_{2}$ for $24 \mathrm{~h}$, and then the culture medium was removed. A $6 \mathrm{mg}$ nanofiber membrane sample was UV-sterilized and added to $1 \mathrm{~mL}$ of culture medium to prepare the leachate. The pure medium was used as the control group, and the leachate was used as the experimental group. Then add them to the corresponding wells. Cells were cultured for $24 \mathrm{~h}$. Next, $10 \mu \mathrm{L}$ of MTT ( $5 \mathrm{mg} / \mathrm{mL}$ ) was added to each well. After the incubation for $4 \mathrm{~h}, 100 \mu \mathrm{L}$ DMSO was appended to each well to dissolve MTT crystals. Samples were analyzed in triplicates for each experiment. The samples' absorbance was measured at a wavelength of $490 \mathrm{~nm}$ by a Microplate reader (Bio TekElx800, Winooski, USA). The relative cell viability (\%) was calculated using the following equation:

$$
\text { Cell viability }(\%)=\frac{\text { ODsample }- \text { ODblank }}{\text { ODcontrol }- \text { ODblank }} \times 100 \% \text {. }
$$

\section{Antibacterial Property}

Use the inoculating ring to scrape the $S$. aureus strains and place them in a conical flask containing $6 \mathrm{~mL}$ of LB broth. It was cultured in a shaker at $37^{\circ} \mathrm{C}$ for $12 \mathrm{~h}$. Prepare agar medium containing LB broth. After cooling, use a sterile cotton swab to dip the culture solution containing $S$. aureus in the Erlenmeyer flask and apply it evenly on the medium's surface. The nanofiber membrane with a diameter of $6 \mathrm{~mm}$ was then placed on a culture plate uniformly coated with a broth containing S. aureus. The diameter of the zone of inhibition was measured after 1 and 7 days. Similarly, the inhibition zone of the nanofiber membrane on the E. coli culture medium was measured.

\section{Animal Wound Model and Histological Analysis}

We used Sprague-Dawley (SD) female rats (Qingdao Daren Fortune Animal Technology Co., Ltd, China) aged 8 weeks with an average weight of $250 \mathrm{~g}$ to evaluate the effect of wound dressings. We randomly (random number table method) divided 
the rats into three groups according to the materials, which were CS-PEO, CS-PEO- $0.5 \% \mathrm{NP} 10$, and gauze group. In the $0.1,0.3$, and $0.5 \%$ NP10 nanofiber membrane group, the CSPEO-0.5\%NP10 group has better morphology and antibacterial properties than the other two groups. So we chose the CS-PEO$0.5 \% \mathrm{NP} 10$ nanofiber membrane group for animal experiments. Each group had six parallel samples. We anesthetized the rats by injecting chloral hydrate $3.5 \%\left(10 \mathrm{~mL} \mathrm{~kg}^{-1)}\right.$ in the abdominal cavity. We prepared one full-thickness round $1.0 \mathrm{~cm}$ diameter wounds by removing dorsal flank skin from the anesthetized rats. After infecting the wounds with $S$. aureus $\left(1 \times 10^{8} \mathrm{CFU}\right.$ $\mathrm{mL}^{-1}, 200 \mu \mathrm{L}$ ) for $30 \mathrm{~min}$, we covered the materials on each rat's dorsal injuries. For histological analysis, we gathered wound tissues from each group of rats on post-operative day 7 and day 14. We put the tissues in a $4 \%$ paraformaldehyde solution. We obtained isometric continuum cut sections using a microtome in vertical planes of each fixed tissue and stained them with H\&E. All animal experiments complied with the ARRIVE guidelines and were carried out by the U.K. Animals (Scientific Procedures) Act, 1986 and associated guidelines, EU Directive 2010/63/EU for animal experiments.

\section{Statistical Analysis}

The data were presented as mean $\pm \mathrm{SD}$, and Student's $t$-test was performed for comparisons. $P$-values were obtained using SPSS 18.0 (SPSS, Chicago, IL, USA). The level of significance was defined as $P<0.05$.

\section{RESULTS AND DISCUSSION}

\section{Characterization of NP10-CS/PEO Nanofibers}

Although chitosan is an excellent material for developing drug delivery systems, including nanofibers, the electrospinability of chitosan is limited (Pakravan et al., 2011). The "spinnability" of chitosan can be improved by blending chitosan with a nonionic polymer such as PEO (Rošic et al., 2012). The smooth nanofibers can be obtained when the ratio of CS to PEO is 50:50 (Zupančič et al., 2016). The nanofiber membranes we prepared are shown in Figure 1. The nanofibers without NP10 contained several beads with a diameter of $53.93 \pm 17.07 \mathrm{~nm}$. The appearance of beading may be related to the precise control of environmental parameters. The relative humidity and temperature of the electrostatic spinning environment parameters reported by Zupančič et al. (2016) are $15 \pm 5 \%$ and 30 $\pm 5^{\circ} \mathrm{C}$, respectively. With the addition of NP10 and an increase in concentration, nanofibers' beading continued to decrease, and the diameter increased to varying degrees. The viscosity of pure CS-PEO solution is $4.63 \pm 0.21 \mathrm{mPa} \cdot \mathrm{s}$, and the viscosity of CSPEO solution with $0.1,0.3$, and $0.5 \% \mathrm{NP} 10$ is $4.72 \pm 0.23 \mathrm{mPa} \cdot \mathrm{s}$, $4.88 \pm 0.31 \mathrm{mPa} \cdot \mathrm{s}, 4.97 \pm 0.19 \mathrm{mPa} \cdot \mathrm{s}$, respectively. When more NP10 was added to the solution, the viscosity became higher. This may be attributed to the increase in diameter. As shown in Figure 1, CS-PEO nanofibers containing 0.5\% NP10 had a better morphology. According to reports, nanofibers with a diameter of $<100 \mathrm{~nm}$ have a large surface area. So they have tremendous potential to adhere to surfaces than thicker nanofibers or polymer films (Zupančič et al., 2016). Therefore, the CS-PEO nanofiber membrane containing NP10 has excellent prospects.

FTIR was used to investigate the molecular interactions between NP10 and CS -PEO nanofiber membranes. Figures 2A,B showed the FTIR spectrum of the CS-PEONP10 nanofiber membranes compared to chitosan, PEO, and NP10 powders. In the FTIR spectrum of pure CS-PEO nanofiber membrane, the absorption band at $2,885 \mathrm{~cm}^{-1}$ is related to $\mathrm{C}-\mathrm{H}$ stretching vibration. The two peaks at 1,477 and $1,355 \mathrm{~cm}^{-1}$ are attributed to the vibrations of amide $\mathrm{N}-\mathrm{H}$ and $\mathrm{C}-\mathrm{H}$ groups of CS. The peaks at $1,100 \mathrm{~cm}^{-1}$ due to $\mathrm{C}-\mathrm{O}-\mathrm{C} ; 839 \mathrm{~cm}^{-1}$ related to the PEO backbone's helical conformation. NP10 is a polypeptide rich in arginine and histidine. All the peaks of CS-PEO nanofiber membranes with different concentrations of NP10 were almost the same as those of pure CS-PEO nanofiber membranes, and only the peak intensity changes. This shows that the addition of NP10 did not change the chemical structure between CS-PEO. The polyether groups of PEO can form hydrogen bonds with the amino groups or hydroxyl groups of chitosan (Zupančič et al., 2016). The amino groups and hydroxyl groups of arginine and histidine in NP10 may enhance this change together with chitosan. According to similar reports by Zupančič et al. (2016) and Deng et al. (2018), this may be the reason for the change in peak intensity in the FTIR spectrum.

To evaluate the thermal stability of the CS-PEO-NP10 nanofiber membrane, a TGA analysis was performed. The graph is shown in Figure 2C. NP10 may have sustained weight loss due to degradation at about $200-460^{\circ} \mathrm{C}$. The TGA thermogram of the nanofiber membrane shows three areas of weight reduction. According to reports, the first zone is between 50 and $150^{\circ} \mathrm{C}$, which may be attributed to the melting temperature of PEO and the evaporation of water and acetic acid remaining in the film (Fazli and Shariatinia, 2017). The second area around $300^{\circ} \mathrm{C}$ may be related to the degradation of chitosan and NP10. The third area is around $380^{\circ} \mathrm{C}$, and the cause may be associated with the degradation of PEO and NP10 (Zupančič et al., 2016). It can be seen from the TGA graph that the weight loss percentage of NP10 was the lowest at $71.33 \%$, which indicated the highest thermal stability. The weight loss percentage of the CS-PEO nanofiber membrane was $84.36 \%$, and the weight loss percentage decreased by $6.05 \%$ after adding $0.5 \%$ NP10. The result demonstrates that adding NP10 can improve the thermal stability of the CS-PEO nanofiber membrane. Strong intermolecular hydrogen bonding and electrostatic interactions between the functional groups of CS and PEO polymers and NP10 drugs may produce a strong network, resulting in a nanocomposite membrane with higher thermal stability than pure CS-PEO nanofibers.

The in vitro release of NP10 in CS-PEO-0.5\% NP10 within 15 days, and the result is plotted in Figure 2D. It was observed that for the CS-PEO nanofiber membrane containing 0.5\% NP10, the drug release increased sharply in the first $24 \mathrm{~h}$ (burst release). In the early $8 \mathrm{~h}$, the average cumulative release of NP10 from nanofibers was $33.4 \%$, and the average cumulative release within $24 \mathrm{~h}$ was $57.1 \%$. After 4 days, the drug will be released very slowly or almost continuously (sustained-release). At 15 days, the average cumulative drug release reached $88.4 \%$. The release mechanism of NP10 from the CS/PEO nanofiber membrane 


\section{A}
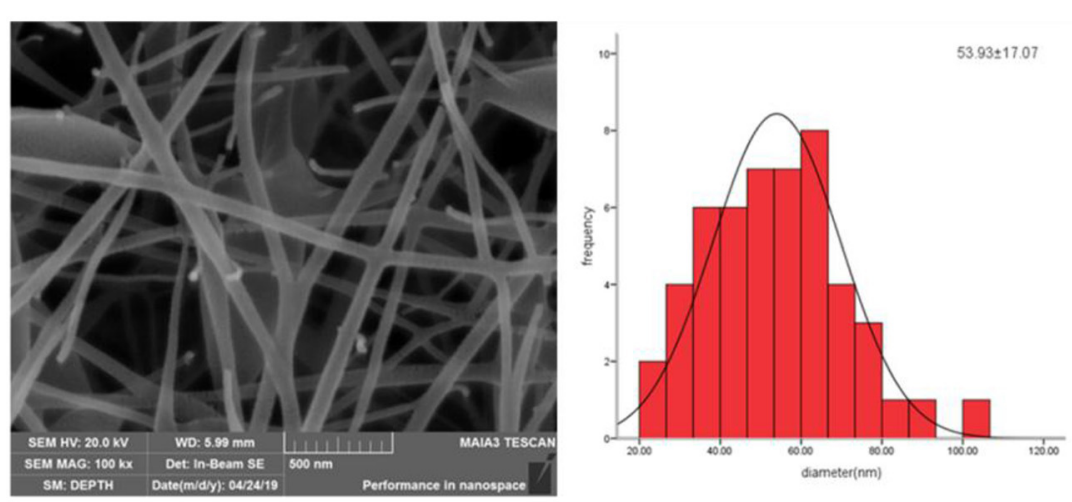

$\mathbf{B}$
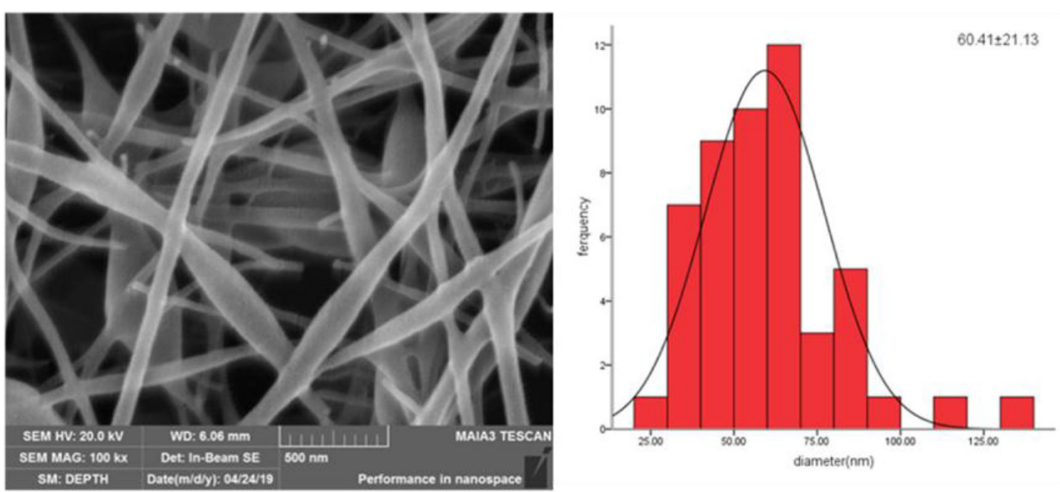

C
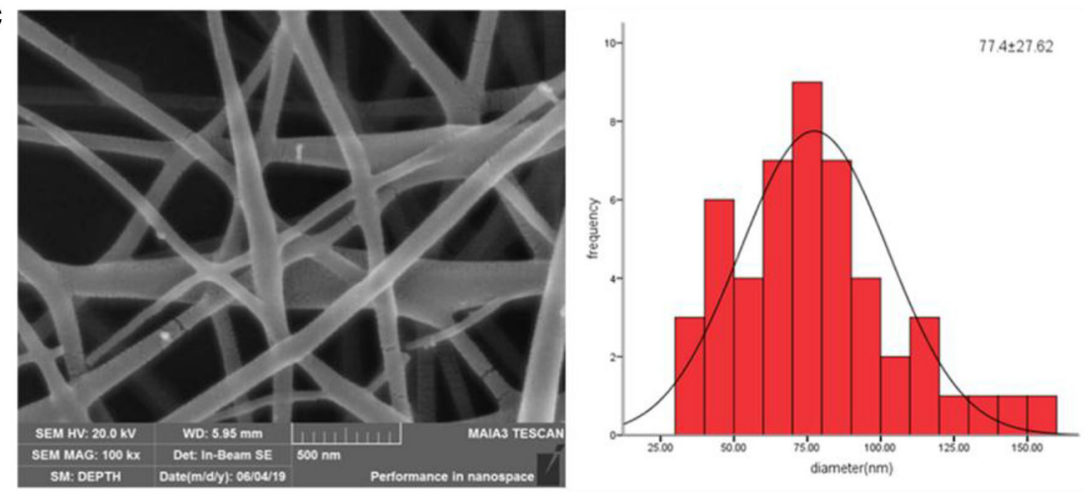

D
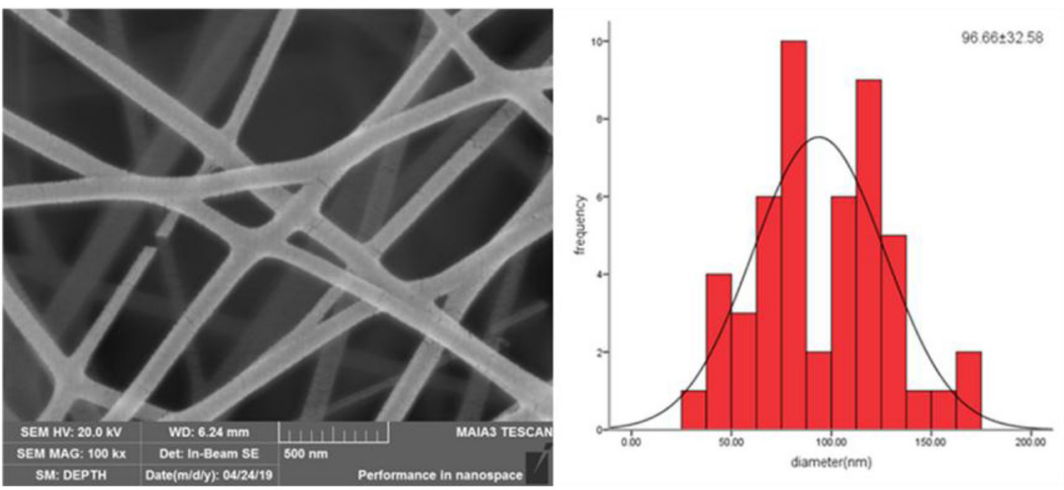

FIGURE 1 | SEM images and fiber diameter(nm) distribution of CS-PEO nanofibers prepared from various contents of NP10: (A) 0\%, (B) 0.1\%, (C) 0.3\%, and (D) $0.5 \%$. 
A

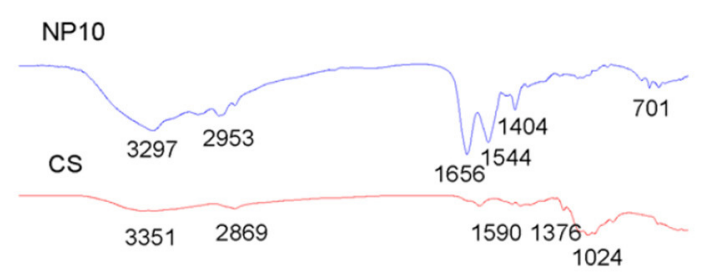

PEO

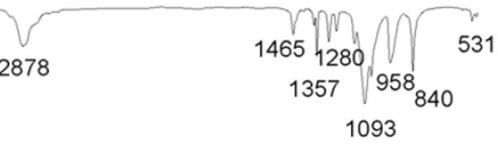

$\begin{array}{llllllll}4000 & 3500 & 3000 & 2500 & 2000 & 1500 & 1000 & 500\end{array}$

C

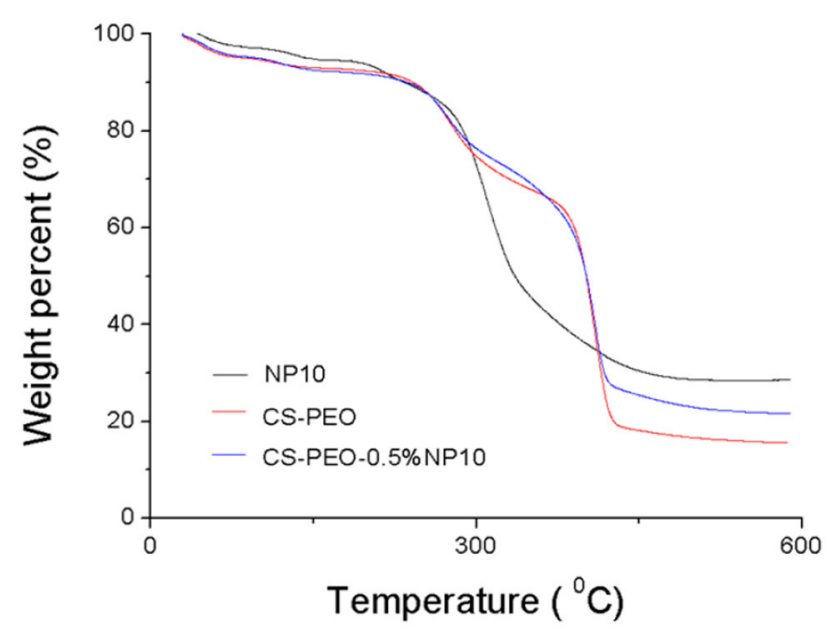

B

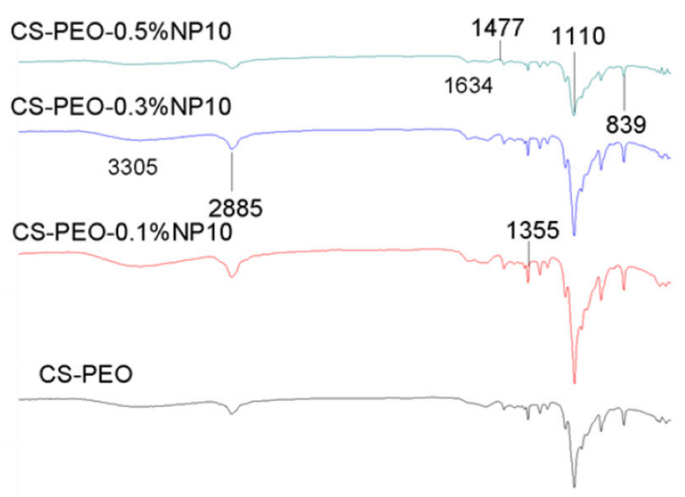

D
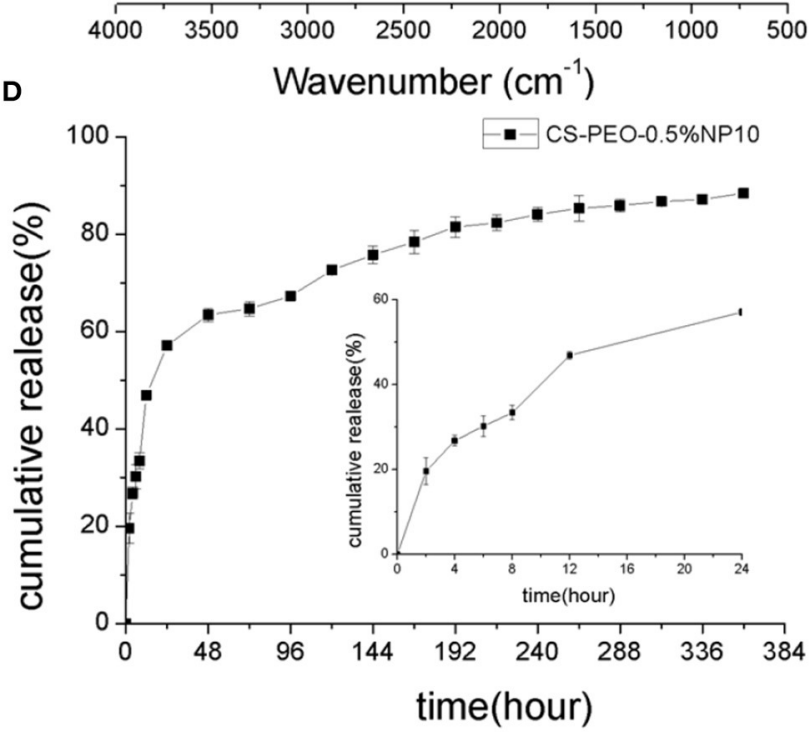

FIGURE 2 | (A) FTIR spectroscopy of the CS, PEO, and NP10 powders. (B) FTIR spectroscopy of CS-PEO nanofiber membranes containing different amounts of NP10. (C) TGA diagrams of NP10, CS-PEO and CS-PEO-0.5\%NP10 nanofiber membranes. (D) In vitro release profile of NP10 (plotted as a function of percentage cumulative release vs. time) from CS-PEO-0.5\%NP10 nanofiber membrane at different time $(n=3)$.

involves the polymer matrix's swelling and erosion (RajabiSiahboomi et al., 1994). When the swellable nanofibers are in contact with the medium, water diffuses into the polymer matrix. It acts as a plasticizer, reducing the polymer-glass transition temperature, leading to glass-rubber transition, gel formation, and polymer chain relaxation (Caccavo et al., 2016). The hydrophilicity of PEO makes it dissolve in PBS, so the pore size of the CS/PEO nanofiber membrane matrix increases (Dart et al., 2019). Due to extensive swelling and matrix erosion, the antimicrobial peptide diffuses out of the CS/PEO nanofiber membrane polymer matrix. The initial burst release may be due to the immediate contact between the nanofiber membrane and the dissolution medium and the leaching of the drug molecules in close contact with the nanofiber membrane's surface. The longerterm extended-release may be due to the more resonant diffusion of drug molecules in the membrane (Ajmal et al., 2019). It is known to apply sterile dressings to wounds to promote healing and prevent further injury. It is also often used in first aid and nursing, so the wound environment must be treated quickly and then continuously (Kohsari et al., 2016b). This indicates that the CS-PEO nanofiber membrane loaded with NP10 can be used as a suitable drug delivery system for biomedical purposes.

From the electrospinning studies of blended solutions completed so far, it seems that hydrophilic polymers are more compatible with AMPs than hydrophobic polymers. Currently, commonly used polymers blended with AMP for spinning include PVA, PEO, etc. This may be due to the more favorable interaction between the hydrophilic polymer and the peptide or the less irritating solvent usually used in the hydrophilic polymer's electrospinning. The hydrophilicity of PEO not only helps to release peptides through dissolution effectively, but it can also be spun with polar and non-polar solvents (Dart et al., 2019). However, hydrophobic polymers such as PCL will not swell unless other surface-active hydrophilic polymers are co-spinned into the fiber system (Han et al., 2017). It has been proven that PCL nanofibers lose antibacterial properties 
A
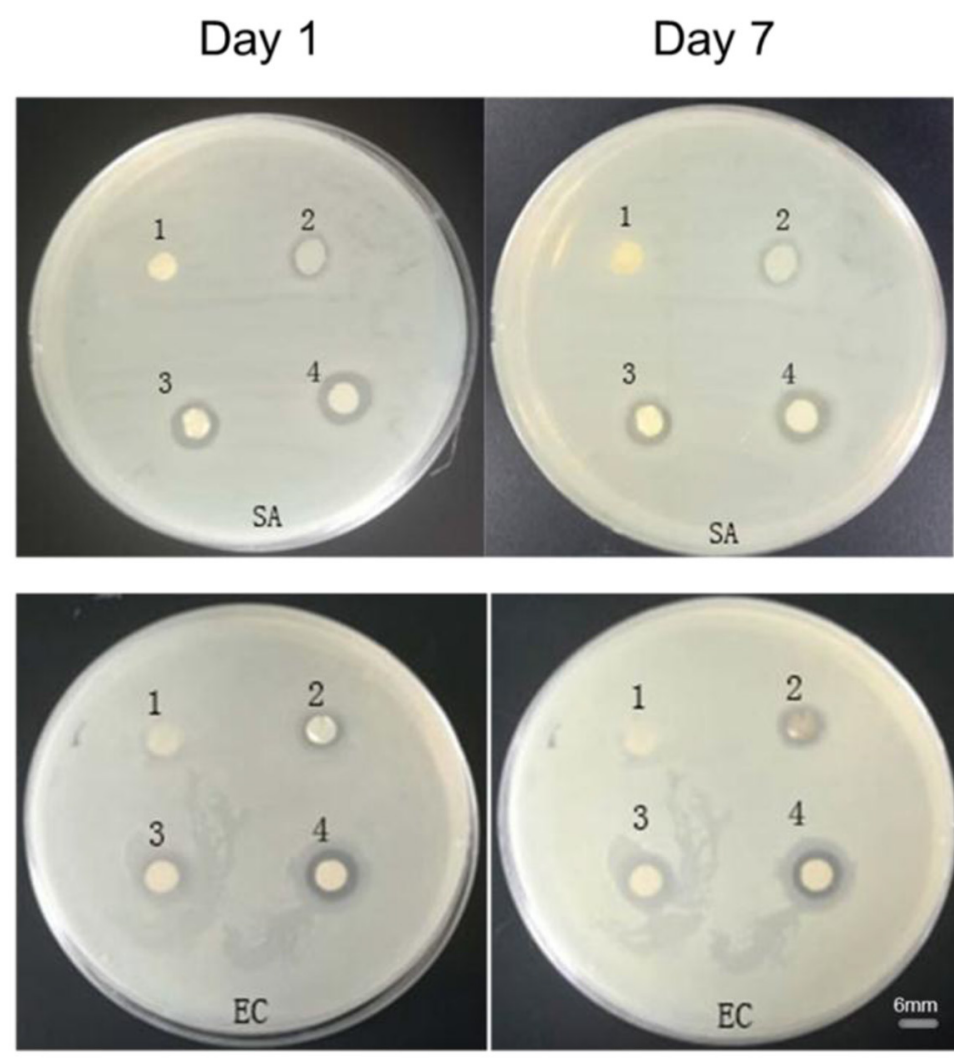

B
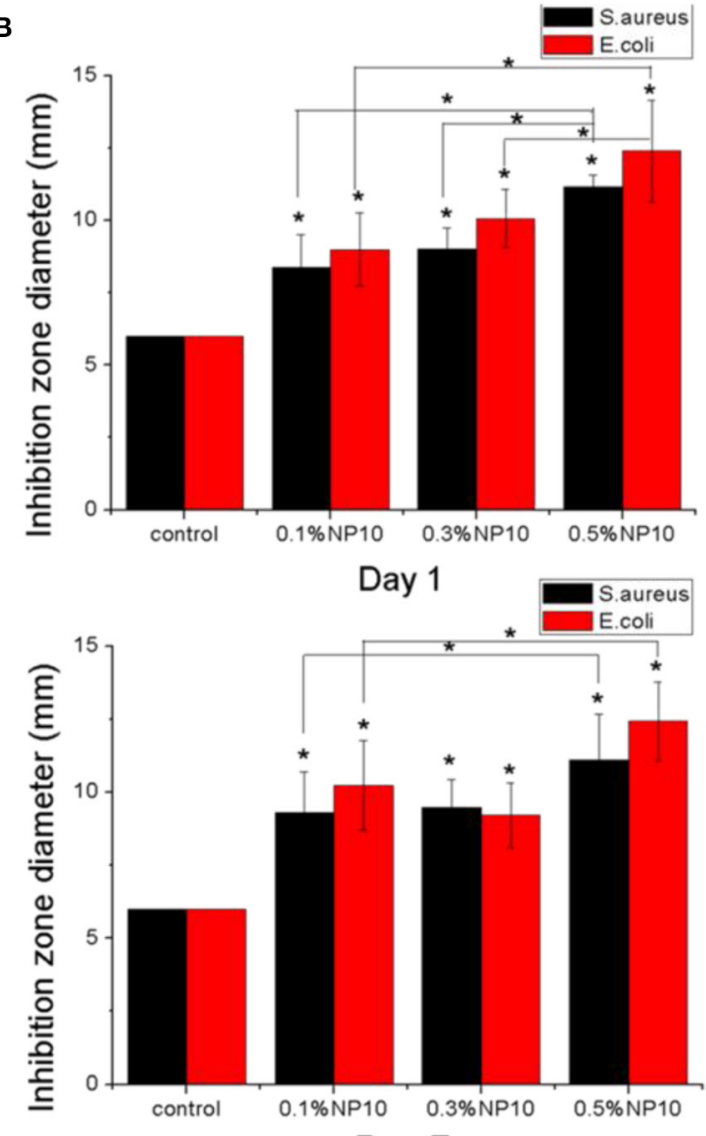

Day 7

FIGURE 3 | (A) Inhibition zones of S. aureus and E. coli on the first and seventh days. The CS-PEO nanofiber membranes contains different amounts of NP10, where SA represents S. aureus and EC represents E. coli [(1) 0\%; (2) 0.1\%; (3) 0.3\%; (4) 0.5\% of NP10]. (B) Calculated suppression zone diameter in (A). Compared with the control group and between the experimental group, ${ }^{*} P<0.05$.

when combined with AMP (Eriksen et al., 2013). The optimal solvent/polymer combination of AMP is critical to its function. At present, there is no report of CS and PEO spinning together with AMP. In the future, more new polymer combinations and other critical biocompatible polymers should be explored, such as polyurethane, poly( $\mathrm{N}$-isopropylacrylamide), and polystyrene (Grace et al., 2017).

\section{Antibacterial Activities Analysis}

The antibacterial activity of CS/ PEO nanofiber membranes, containing various amounts of NP10 against Gram-positive $S$. aureus and Gram-negative E. coli, was tested by the inhibition zone test.

As shown in Figure 3, no inhibition zone was observed around the membrane composed of NP10-free nanofibers. However, there was a significant inhibition zone around the NP10-loaded nanofiber composites. Compared with the control group, each group containing NP10 had a statistical difference in the inhibition zone's diameter. This indicates that the nanofiber membrane loaded with NP10 can inhibit bacteria's growth and has vigorous antibacterial activity. The higher the concentration of NP10 in the fiber, the larger the inhibition zone formed around the nanofiber membrane. There was no statistical difference in the inhibition zone's diameter between the nanofiber membranes loaded with $0.1 \%$ NP10 and $0.3 \%$ NP10. However, these two groups were statistically different from the group loaded with $0.5 \%$ NP10 on the first day. The nanofiber membrane loaded with $0.5 \% \mathrm{NP} 10$ had the most potent antibacterial properties.

We observed and measured the inhibition zone size of each nanofiber membrane on the seventh day. The diameter of the inhibition zone of the nanofiber membrane group loaded with $0.3 \%$ NP10 decreased. No matter of E. coli or S. aureus, the inhibition zone's size around other group nanofiber membrane measured on the seventh day was similar to that on the first day. This indicates that long-acting when the width of the zone of inhibition increases with time. Meanwhile, the results showed that the area of inhibition of E. coli was usually more extensive than that of $S$. aureus. It can be attributed to the more substantial effect of the CS-PEO-NP10 nanofiber membrane on E. coli. This is mainly due to the structural differences between Gram-positive and Gram-negative bacteria on the cell 

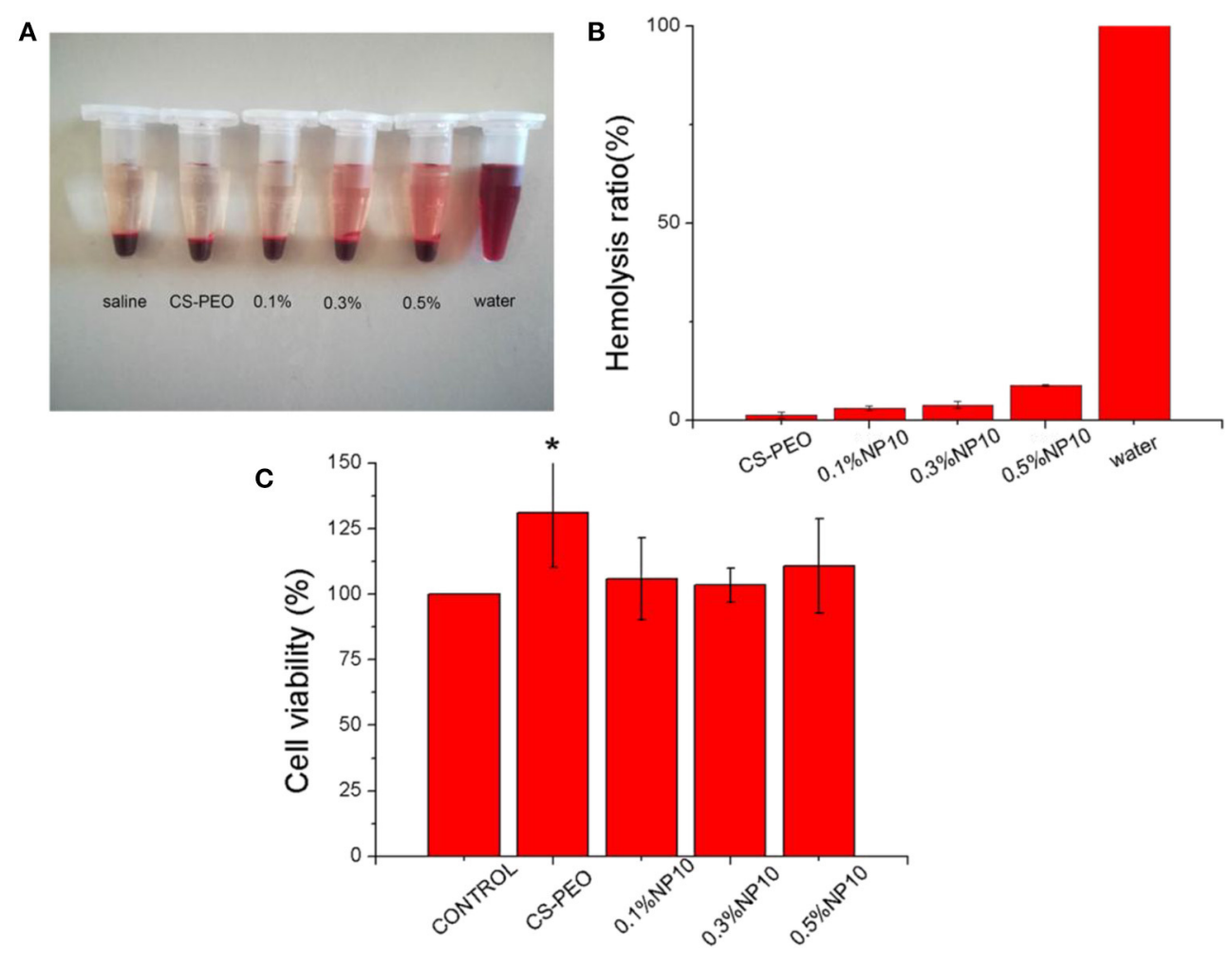

FIGURE 4 | (A) Photographs of fresh human blood incubated with different concentrations of CS-PEO-NP10. (B) Hemolysis ratio of different concentrations of CS-PEO-NP10. (C) MTT assays of CS-PEO-NP10 nanofibers with different amounts of NP10. The data represented mean and standard deviations of the 6 samples. Compared with the control group, ${ }^{\star} P=0.025$.

wall. The cell walls of gram-positive bacteria are very thick $(15-30 \mathrm{~nm})$, rich in peptidoglycans and other polymers, such as neutral polysaccharides, teichoic acids, teichuronic acids, lipoteichoic acids, and glycolipids. Gram-negative bacteria are composed of an outer membrane containing phospholipids, lipopolysaccharides, proteins, and a peptidoglycan layer between the inner and outer membranes. Gram-negative bacteria are more involved in structure and chemistry than Gram-positive bacteria. However, all bacterial membranes contain many negatively-charged molecules, which will affect their interaction with AMP (Yokoyama et al., 1988). In gram-positive bacteria, D-alanylation of wall teichoic and lipoteichoic acids reduce the net negative charge and confers relative protection against AMPs. S. aureus lacking D-alanine in lipoteichoic acids has increased cell surface electronegativity and is more sensitive to cations and pore-forming AMPs (Koprivnjak and Peschel, 2011).

At present, there are many mechanisms of AMPs, including carpet model, barrel wall model, ring hole model, etc.. The pores are formed through the interaction of peptides and lipids. Other specific or less common mechanisms of action of antimicrobial peptides include membrane thickening/thinning, charged lipid aggregation, nucleic acid-targeting, anion carriers, and electroporation, non-cleavable membrane depolarization, and non-bilayer intermediates. Cationic amphiphilic AMPs are well-known and have been studied for decades. However, the exact mechanism of their interaction with membranes and cells is still not fully understood. It is generally believed that peptides initially interact with microbial membranes through electrostatic interactions, and electrostatic interactions are achieved by the cationic of AMPs and the net negative charge of bacterial membranes. When AMPs contact the membrane, hydrophobic interactions play a crucial role, thus highlighting amphiphilicity as an essential mechanistic feature of this peptide family (Torres et al., 2019). When the highly cationic amphiphilic peptides are arranged parallel to the membrane surface, the hydrophobic region is located above the bilayer's center. This causes the lipid fatty acyl chains to move below the helical domain and is accompanied by the accumulation of fatty acyl chains and membrane thinning, leading to membrane lysis or peptide incorporation into cells. Solid-state NMR measurements in the presence of ergotin and other amphiphilic peptides did monitor the changes in order parameters within the lipid bilayer consistent with this mechanism. The double-layer destruction scope is far beyond the immediate area of the peptide inserted into the membrane (Bechinger, 2015).

A recent study showed that arginine-rich AMP MP196 competes with the association of surrounding membrane proteins. This effect may be driven by electrostatic interactions and may further regulate the peptide's surface on the membrane (Wenzel et al., 2015). Similar to MP196, NP10 contains arginine 


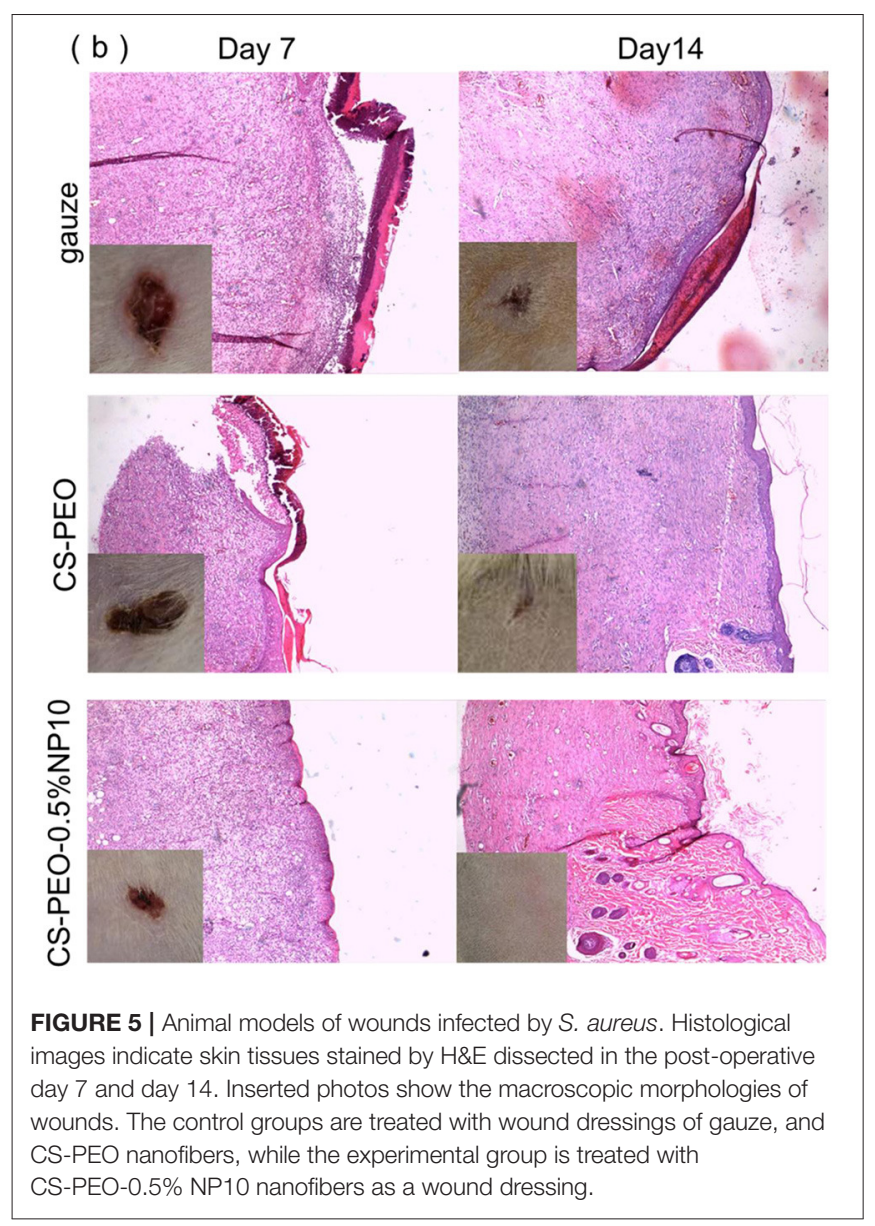

and histidine and is a cationic amphiphilic antimicrobial peptide. The antibacterial mechanism may involve the AMPs with net positive charges attracting the negative electrostatic charges on the surface of bacteria, which adheres to the bacterial cell membrane. It is then inserted into bacterial, causing the cell membrane to rupture, destroying the bacterial cell membrane's integrity, and eventually leading to cell death.

\section{Biological Safety of Nanofiber Membrane}

To study biocompatibility, we tested the hemolytic properties of human red blood cells (Figure 4). Hemolysis must be avoided when used in materials in contact with blood, such as wound contact dressings. When the nanofiber membrane concentration NP10 is $0.5 \%$, the hemolysis rate is higher, $8.86 \%$ (>5\%), but $<10 \%$. It shows that nanofiber membranes loaded with different concentrations of NP10 have well-biocompatibility. Because compounds that cause hemolysis $<10 \%$ are considered nonhemolytic or blood compatible, compounds that cause hemolysis $>25 \%$ are classified as hemolytic (Amin and Dannenfelser, 2006). The hemolysis rate of other nanofiber membranes was $<0.5 \%$, indicating a better biological safety.

HPA3NT3, a positively charged AMP, is electrospun together with $\mathrm{PEO}$ into nanofibers, and its activity against $S$. aureus and $E$. coli is not reduced. However, later studies have shown that HPA3NT3 is cytotoxic to Hacat cells, limiting its use in wound healing applications (Dart et al., 2019). For further clinical safety assessment, we tested the cytotoxicity of each nanofiber membrane using Hacat cells. After the addition of NP10 nanofiber membrane leachate at different concentrations, we found no statistically significant difference in cell activity between the control group and the control group at $24 \mathrm{~h}$, which implies that the nanofiber membrane leachate added with NP10 was non-cytotoxic. The CS-PEO nanofiber membrane group, with higher cell viability, was significantly different from the control group $(P=0.025)$. This demonstrates that the pure CSPEO nanofiber membrane is non-cytotoxic and may promote cell proliferation.

\section{Animal Evaluation}

At present, many studies have proved that AMP also plays a vital role in promoting cell migration and proliferation, the production of chemokines and cytokines, and wound healing. Human beta-defensins have antibacterial activity and immunomodulatory function and promote endothelial cell proliferation and keratinocyte migration and proliferation $(\mathrm{Mi}$ et al., 2018). Plantaricin A has been proved to increase cell proliferation and migration. It also can influence the expression of transforming growth factor 1, fibroblast growth factor 7 , vascular endothelial growth factor $\mathrm{A}$, and interleukin-8 in vitro in human keratinocytes. Nisin $\mathrm{Z}$ has been shown to have immunomodulatory activity and modulates the host immune response similar to the natural host defense peptide (Wenzel et al., 2015). To test the nanofiber membrane's practical applicability, we investigated the performance in skin wound healing through a dorsal wound model of rats exposed to $S$. aureus. We treated each rat with $S$. aureus to establish a bacterial wound infection model. After that, we used CS-PEO-0.5\% NP10 electrospun nanofiber membrane, CS-PEO nanofiber membrane, and gauze (traditional wound dressing) as wound dressings.

To further investigate the process of wound healing, we photographed infected full-thickness wounds on post-operative days 7,14 . We examined the wound by histological analysis with hematoxylin and eosin (H \& E) staining (Figure 5). On day 7 after surgery, scars formed on all wounds infected with $S$. aureus. The damage treated with CS-PEO-0.5\% NP10 nanofiber membrane was smaller than other injuries. Histological images showed a large number of inflammatory cells in all wounds, which implies an inflammatory response.

After 14 days, the area of all wounds was significantly reduced. The wound area of the CS-PEO nanofiber membrane group and the CS-PEO-0.5\%NP10 nanofiber membrane group was smaller than that of the gauze group. The CS-PEO-0.5\%NP10 nanofiber membrane group had the smallest wound area, and some wounds were healed. The histological image showed that it was close to normal skin tissue. Elongated fibroblasts, epithelial cells, and stratum corneum were present in all wound dressing groups while varying numbers of inflammatory cells remained. The new skin epidermal layer and dermal layer were well-delaminated. The CS-PEO-0.5\% NP10 group had more mature fibroblasts than the CS-PEO group. The wound healing process's main steps are re-epithelialization and granulation tissue formation (Reynolds 
et al., 2005; Xie et al., 2011). The migration and proliferation of fibroblasts and epidermal cells are signals of re-epithelialization. Elongated fibroblasts help to form mature fibrous granulation tissue (Akasaka et al., 2004). Compared with the gauze group, the CS-PEO group and the CS-PEO-0.5\% NP10 group had more new blood vessels. The formation of new blood vessels is significant for the tissue remodeling process. It involves delivering and penetrating various substances into the wound, such as oxygen, nutrients, cells, and growth factors. Some studies have shown that antimicrobial peptides used in wound treatment can enhance new blood vessels' formation. For example, Zefeng Lin fixes AMP Tet213 on a substrate of alginate (ALG), hyaluronic acid (HA), and collagen (COL) to form an ALG/HA/COL-AMP wound dressing, which can promote the formation of new blood vessels (Lin et al., 2019). In short, the CS-PEO-0.5\%NP10 nanofiber membrane has advantages in promoting wound healing.

According to reports, three nanofiber studies on AMP were tested in vivo on mouse wounds (Dart et al., 2019). Heunis et al. first reported in 2013 an in vivo experiment using electrospinning technology to spin AMP into nanofibers to treat skin infections caused by bacteria. In a mouse model, PEO-PDLLA nanofibers containing nisin can reduce the bacterial burden of wounds infected by $S$. aureus and facilitate the healing time of uninfected wounds. However, there is no difference between it and gauze in the healing of infected wounds. That is, it cannot promote the healing of infected wounds (Heunis et al., 2013). Studies by Sebe et al. have shown that PVA nanofibers combined with AMP APO have successfully improved wound healing in vivo. APO has prominent antibacterial properties against Acinetobacter baumannii. In an in vivo mouse wound model, $A$. baumannii was introduced into the wound to evaluate the wound healing ability of AMP APO-loaded fibers. After AMP APO is loaded into ESF, it has an antibacterial effect and promotes the healing of non-infected wounds and infected wounds. Besides, non-infected wounds heal better than infected wounds (Sebe et al., 2016). Chouhan et al. used PVA nanofibers mixed with AMP LL-37 to treat non-infected injuries in a mouse diabetes model. The wounds closed after 14 days, while the gauze group wounds closed after 21 days. PVA nanofibers containing LL37 also retain their efficacy as anti-Staphylococcus epidermidis and Pseudomonas aeruginosa. Although these studies have confirmed that the nanofiber membrane containing AMP has a positive effect on antibacterial and wound healing (Chouhan et al., 2018), these studies lack the nanofiber membrane system research and characterization biocompatibility, and other aspects are not involved. This research systematically studied

\section{REFERENCES}

Abrigo, M., McArthur, S. L., and Kingshott, P. (2014). Electrospun nanofibers as dressings for chronic wound care: advances, challenges, and future prospects. Macromol. Biosci. 14, 772-792. doi: 10.1002/mabi.201300561

Ajmal, G., Bonde, G. V., Thokala, S., Mittal, P., Khan, G., Singh, J., et al. (2019). Ciprofloxacin $\mathrm{HCl}$ and quercetin functionalized electrospun nanofiber membrane: fabrication and its evaluation in full thickness wound healing. Artif. Cells Nanomed. Biotechnol. 47, 228-240. doi: 10.1080/21691401.2018.1548475 the characterization, antibacterial properties, biocompatibility. It wound healing ability of CS-PEO nanofiber membranes loaded with different concentrations of NP10, providing a more comprehensive evaluation for its clinical application and treatment of infected wounds, offers more possibilities.

\section{CONCLUSIONS}

We prepared nanofiber membranes containing different concentrations of AMPs NP10 with excellent antibacterial and biocompatibility. In our research, the CS-PEO-0.5\%NP10 nanofiber membrane had the best morphology and antibacterial ability, as well as good biocompatibility and wound healing ability. In the in vitro release experiment, NP10 was released from the CS-PEO-0.5\%NP10 nanofiber membrane in a burst first and then slowly and continuously. These properties may provide a choice for the clinical application of AMPs and treatment of wound infections.

\section{DATA AVAILABILITY STATEMENT}

The original contributions presented in the study are included in the article/supplementary material, further inquiries can be directed to the corresponding author/s.

\section{ETHICS STATEMENT}

The animal study was reviewed and approved by Experimental Animal Ethics Committee of Weifang Medical College.

\section{AUTHOR CONTRIBUTIONS}

LY, SD, and MZ conducted experiments, data collection, and analysis. JM, QG, and ML were involved in the writing, revision, and image finishing of the thesis. WZ conducts fund approval and article submission. XZ and WZ provided ideas and revised the article. All authors contributed to the article and approved the submitted version.

\section{FUNDING}

This work was supported by a grant from the National Natural Science Foundation of China (Nos. 81774125 and 81973671) and the major innovation and technology engineering project of Shandong Province (2019JZZY011106). 
Bechinger, B. (2015). The SMART model: soft membranes adapt and respond, also transiently, in the presence of antimicrobial peptides. J. Pept. Sci. 21, 346-355. doi: $10.1002 /$ psc. 2729

Blyth, D. M., Yun, H. C., Tribble, D. R., and Murray, C. K. (2015). Lessons of war: combat-related injury infections during the vietnam war and operation iraqi and enduring freedom. J. Trauma Acute Care Surg. 79(4 Suppl. 2), S227-S235. doi: 10.1097/TA.0000000000000768

Caccavo, D., Cascone, S., Lamberti, G., Barba, A. A., and Larsson, A. (2016). Swellable hydrogelbased systems for controlled drug delivery. Smart Drug Deliv. Syst. 14:179-189. doi: 10.5772/61792

Champion, H. R., Bellamy, R. F., Roberts, C. P., and Leppaniemi, A. (2003). A profile of combat injury. J. Trauma 54(Suppl. 5):S13-S19. doi: 10.1097/01.TA.0000057151.02906.27

Chouhan, D., Janani, G., Chakraborty, B., Nandi, S. K., and Mandal, B. B. (2018). Functionalized PVA-silk blended nanofibrous mats promote diabetic wound healing via regulation of extracellular matrix and tissue remodelling. J. Tissue Eng. Regen. Med. 12, e1559-e1570. doi: 10.1002/ term. 2581

Dart, A., Bhave, M., and Kingshott, P. (2019). Antimicrobial peptidebased electrospun fibers for wound healing applications. Macromol. Biosci. 19:e1800488. doi: 10.1002/mabi.201800488

Deng, L., Taxipalati, M., Zhang, A., Que, F., Wei, H., Feng, F., et al. (2018). Electrospun chitosan/poly(ethylene oxide)/lauric arginate nanofibrous film with enhanced antimicrobial activity. J. Agric. Food Chem. 66, 6219-6226. doi: 10.1021 acs.jafc. 8 b01493

Dewangan, R. P., Bisht, G. S., Singh, V. P., Yar, M. S., and Pasha, S. (2018). Design and synthesis of cell selective $\alpha / \beta$-diastereomeric peptidomimetic with potent in vivo antibacterial activity against methicillin resistant $S$. aureus. Bioorg. Chem. 76, 538-547. doi: 10.1016/j.bioorg.2017.12.020

Eriksen, T. H., Skovsen, E., and Fojan, P. (2013). Release of antimicrobial peptides from electrospun nanofibres as a drug delivery system. J. Biomed. Nanotechnol. 9, 492-498. doi: 10.1166/jbn.2013.1553

Fan, J., Lei, T. D., and Li, J. (2016). High protein content keratin/poly(ethylene oxide) nanofibers crosslinked in oxygen atmosphere and its cell culture. Mater Des. 104, 60-67. doi: 10.1016/j.matdes.2016.05.022

Fares, Y., El-Zaatari, M., Fares, J., Bedrosian, N., and Yared, N. (2013). Traumarelated infections due to cluster munitions. J. Infect. Public Health 6, 482-486. doi: 10.1016/j.jiph.2013.05.006

Fazli, Y., and Shariatinia, Z. (2017). Controlled release of cefazolin sodium antibiotic drug from electrospun chitosan-polyethylene oxide nanofibrous Mats. Mater. Sci. Eng. C Mater. Biol. Appl. 71, 641-652. doi: 10.1016/j.msec.2016.10.048

Felgueiras, H. P., and Amorim, M. T. P. (2017). Functionalization of electrospun polymeric wound dressings with antimicrobial peptides. Coll. Surf. B Biointerfaces 156, 133-148. doi: 10.1016/j.colsurfb.2017.05.001

Giannou, C., and Baldan, M. (2010). War Surgery: Working with Limited Resources in Armed Conflict and Other Situations of Violence. Geneva: International Committee of the Red Cross. Switzerland.

Gordon, Y. J., Romanowski, E. G., and McDermott, A. M. (2005). A review of antimicrobial peptides and their therapeutic potential as antiinfective drugs. Curr. Eye Res. 30, 505-515. doi: 10.1080/027136805909 68637

Grace, J. L., Elliott, A. G., Huang, J. X., Schneider, E. K., Truong, N. P., Cooper, M. A., et al. (2017). Cationic acrylate oligomers comprising amino acid mimic moieties demonstrate improved antibacterial killing efficiency. J. Mater. Chem. B 5, 531-536. doi: 10.1039/С6TB02787C

Guan, M., Xie, J., and Xue, B. (2016). Effect of sodium citrate on properties of chitosan/soybean protein isolate composite films. Sci Technol Food Ind. 37, 277-280. doi: 10.1111/j.77-280.2016.tb00588

Han, D., Sherman, S., Filocamo, S., and Steckl, A. J. (2017). Long-term antimicrobial effect of nisin released from electrospun triaxial fiber membranes. Acta Biomater. 53, 242-249. doi: 10.1016/j.actbio.2017.02.029

Hancock, R. E. (1997). Peptide antibiotics. Lancet 349, 418-422. doi: 10.1016/S0140-6736(97)80051-7

Heunis, T. D., Smith, C., and Dicks, L. M. (2013). Evaluation of a nisin-eluting nanofiber scaffold to treat Staphylococcus aureus-induced skin infections in mice. Antimicrob. Agents Chemother. 57, 3928-3935. doi: 10.1128/AAC.00622-13
Huang, C.-F., and Chang, F.-C. (2003). Comparison of hydrogen bonding interaction between PMMA/PMAA blends and PMMA-co-PMAA copolymers. Polymer 44, 2965-2974. doi: 10.1016/S0032-3861(03)00188-5

Hunley, M. T., and Long, T. E. (2008). Electrospinning functional nanoscale fibers: a perspective for the future. Polym. Int. 57, 385-389. doi: 10.1002/pi.2320

Infectious Diseases Society of America (IDSA), Spellberg, B., Blaser, M., Guidos, R. J., Boucher, H. W., Bradley, J. S., et al. (2011). Combating antimicrobial resistance: policy recommendations to save lives. Clin. Infect. Dis. 52(Suppl. 5):S397-S428. doi: 10.1093/cid/cir153

Jannesari, M., Varshosaz, J., Morshed, M., and Zamani, M. (2011). Composite poly(vinyl alcohol)/poly(vinyl acetate) electrospun nanofibrous mats as a novel wound dressing matrix for controlled release of drugs. Int. J. Nanomedicine 6, 993-1003. doi: 10.2147/IJN.S17595

Jin, H. J., Fridrikh, S. V., Rutledge, G. C., and Kaplan, D. L. (2002). Electrospinning Bombyx mori silk with poly(ethylene oxide). Biomacromolecules 3, 1233-1239. doi: 10.1021/bm025581u

Johansson, J., Gudmundsson, G. H., Rottenberg, M. E., Berndt, K. D., and Agerberth, B. (1998). Conformation-dependent antibacterial activity of the naturally occurring human peptide LL-37. J. Biol. Chem. 273, 3718-3724. doi: $10.1074 / j b c .273 .6 .3718$

Jones, V., Grey, J. E., and Harding, K. G. (2006). Wound dressings. BMJ 332, 777-780. doi: 10.1136/bmj.332.7544.777

Kohsari, I., Shariatinia, Z., and Pourmortazavi, S. M. (2016a). Antibacterial electrospun chitosan-polyethylene oxide nanocomposite mats containing ZIF-8 nanoparticles. Int. J. Biol. Macromol. 91, 778-788. doi: 10.1016/j.ijbiomac.2016.06.039

Kohsari, I., Shariatinia, Z., and Pourmortazavi, S. M. (2016b). Antibacterial electrospun chitosan-polyethylene oxide nanocomposite mats containing bioactive silver nanoparticles. Carbohydr. Polym. 140, 287-298. doi: 10.1016/j.carbpol.2015.12.075

Koprivnjak, T., and Peschel, A. (2011). Bacterial resistance mechanisms against host defense peptides. Cell Mol. Life Sci. 68, 2243-2254. doi: 10.1007/s00018-011-0716-4

Lannutti, J., Reneker, D., and Ma, T. (2007). Electrospinning for tissue engineering scaffolds. Mater. Sci. Eng. C 27, 504-509. doi: 10.1016/j.msec.2006.05.019

Li, J., Lei, T. D., and Wang, Y. H. (2016). Preparation and characterization of high-content keratin/PEO nanofiber using organic solvent. J. Donghua Univ. 42, 793-799. doi: 10.2174/187412070161001025

Liang, D., Hsiao, B. S., and Chu, B. (2007). Functional electrospun nanofibrous scaffolds for biomedical applications. Adv. Drug Deliv. Rev. 59, 1392-1412. doi: 10.1016/j.addr.2007.04.021

Lin, Z., Wu, T., Wang, W., Li, B., Wang, M., Chen, L., et al. (2019). Biofunctions of antimicrobial peptide-conjugated alginate/hyaluronic acid/collagen wound dressings promote wound healing of a mixed-bacteria-infected wound. Int. J. Biol. Macromol. 140, 330-342. doi: 10.1016/j.ijbiomac.2019.08.087

Mangoni, M. L., McDermott, A. M., and Zasloff, M. (2016). Antimicrobial peptides and wound healing: biological and therapeutic considerations. Exp. Dermatol. 25, 167-173. doi: 10.1111/exd.12929

Martí, M., Frígols, B., and Serrano-Aroca, A. (2018). Antimicrobial characterization of advanced materials for bioengineering applications. $J$. Vis. Exp. 2018:57710. doi: 10.3791/57710

Mi, B., Liu, J., Liu, Y., Hu, L., Liu, Y., Panayi, A. C., et al. (2018). The designer antimicrobial peptide A-hBD-2 facilitates skin wound healing by stimulating keratinocyte migration and proliferation. Cell Physiol. Biochem. 51, 647-663. doi: 10.1159/000495320

Murray, C. J., King, G., Lopez, A. D., Tomijima, N., and Krug, E. G. (2002). Armed conflict as a public health problem. BMJ. 324, 346-349. doi: $10.1136 /$ bmj. 324.7333 .346

Pacor, S., Giangaspero, A., Bacac, M., Sava, G., and Tossi, A. (2002). Analysis of the cytotoxicity of synthetic antimicrobial peptides on mouse leucocytes: implications for systemic use. J. Antimicrob. Chemother. 50, 339-348. doi: $10.1093 / \mathrm{jac} / \mathrm{dkf1} 14$

Pakravan, M., Heuzey, M., and Ajji, A. (2011). A fundamental study of chitosan/PEO electrospinning. Polymer 52, 4813-4824. doi: 10.1016/j.polymer.2011.08.034

Rajabi-Siahboomi, A. R., Bowtell, R. W., Mansfield, P., Henderson, A., Davies, M. C., and Melia, C. D. (1994). Structure and behaviour in hydrophilic matrix sustained release dosage forms: 2. NMR-imaging studies of dimensional 
changes in the gel layer and core of HPMC tablets undergoing hydration. $J$. Control. Release 31, 121-128. doi: 10.1016/0168-3659(94)00016-6

Reynolds, L. E., Conti, F. J., Lucas, M., Grose, R., Robinson, S., Stone, M., et al. (2005). Accelerated re-epithelialization in beta3-integrin-deficient- mice is associated with enhanced TGF-betal signaling. Nat. Med. 11, 167-174. doi: $10.1038 / \mathrm{nm} 1165$

Rice, L. B. (2008). Federal funding for the study of antimicrobial resistance in nosocomial pathogens: no ESKAPE. J. Infect. Dis. 197, 1079-1081. doi: $10.1086 / 533452$

Rošic, R., Pelipenko, J., and Kocbek, P. (2012). The role of rheology of polymer solutions in predicting nanofiber formation by electrospinning. Eur. Polym. J. 48, 1374-1384. doi: 10.1016/j.eurpolymj.2012. 05.001

Sahli, Z. T., Bizri, A. R., and Abu-Sittah, G. S. (2016). Microbiology and risk factors associated with war-related wound infections in the Middle East. Epidemiol. Infect. 144, 2848-2857. doi: 10.1017/S0950268816000431

Sebe, I., Ostorhazi, E., Fekete, A., Kovacs, K. N., Zelko, R., Kovalszky, I., et al. (2016). Polyvinyl alcohol nanofiber formulation of the designer antimicrobial peptide APO sterilizes Acinetobacter baumannii-infected skin wounds in mice. Amino Acids 48, 203-211. doi: 10.1007/s00726-015-2080-4

Torres, M. D. T., Sothiselvam, S., Lu, T. K., and de la Fuente-Nunez, C. (2019). Peptide design principles for antimicrobial applications. J. Mol. Biol. 431, 3547-3567. doi: 10.1016/j.jmb.2018.12.015

Wenzel, M., Senges, C. H., Zhang, J., Suleman, S., Nguyen, M., Kumar, P., et al. (2015). Antimicrobial peptides from the aurein family form ion-selective pores in Bacillus subtilis. ChemBioChem 16, 1101-1108. doi: 10.1002/cbic.201500020

World Health Organization (2014). Antimicrobial Resistance: 2014 Global Report on Surveillance. Geneva: World Health Organization.
Xie, Y. Y., Zhang, W., and Wang, L. M. (2011). A microchip-based model wound with multiple types of cells. Lab Chip. 11, 2819-2822. doi: 10.1039/c0lc0 0562b

Yokoyama, K., Araki, Y., and Ito, E. (1988). The function of galactosyl phosphorylpolyprenol in biosynthesis of lipoteichoic acid in Bacillus coagulans. Eur. J. Biochem. 173, 453-458. doi: 10.1111/j.1432-1033.1988.tb1 4020.x

Zasloff, M. (2002). Antimicrobial peptides of multicellular organisms. Nature 415, 389-395. doi: 10.1038/415389a

Zhao, P., Xue, Y., Gao, W., Li, J., Zu, X., Fu, D., et al. (2018). Bacillaceae-derived peptide antibiotics since 2000. Peptides 101, 10-16. doi: 10.1016/j.peptides.2017.12.018

Zupančič, Š., Potrč, T., Baumgartner, S., Kocbek, P., and Kristl, J. (2016). Formulation and evaluation of chitosan/polyethylene oxide nanofibers loaded with metronidazole for local infections. Eur. J. Pharm. Sci. 95, 152-160. doi: $10.1016 /$ j.ejps.2016.10.030

Conflict of Interest: The authors declare that the research was conducted in the absence of any commercial or financial relationships that could be construed as a potential conflict of interest.

Copyright ( $2021 \mathrm{Yu}$, Dou, Ma, Gong, Zhang, Zhang, Li and Zhang. This is an open-access article distributed under the terms of the Creative Commons Attribution License (CC BY). The use, distribution or reproduction in other forums is permitted, provided the original author $(s)$ and the copyright owner(s) are credited and that the original publication in this journal is cited, in accordance with accepted academic practice. No use, distribution or reproduction is permitted which does not comply with these terms. 